\title{
Good glycaemic control reduces oxidation and glycation end-products in collagen of diabetic rats
}

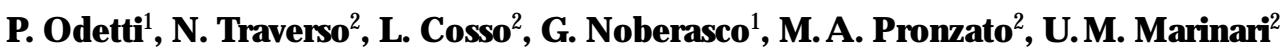 \\ ${ }^{1}$ D epartment of I nternal M edicine (DI .M .I.), U niversity of $G$ enoa, I taly \\ ${ }^{2}$ Institute of $G$ eneral Pathology, $U$ niversity of $G$ enoa, I taly
}

Summary Blood glucose control plays a prominent role in the aetiology of diabetic complications. R ecent data support the hypothesis that non-enzymatic pathways (glycation and oxidation) are involved in the pathogenesis of tissue damage in diabetes mellitus. In this study the level of pentosidine, a marker of glycation, and the intensity of collagen-linked fluorescence glycation (370/440 and 335/385 nm) and oxidation-related (356/460 and 390/460 $\mathrm{nm}$ ), have been examined in spontaneously diabetic rats with good and poor glycaemic control. Pentosidine increased dramatically in rats with poor control, and slightly in those with good control. A t the end of the study, after 6 months of diabetes, pentosidine levels were $13 \pm 5$ and $2.1 \pm 0.5 \mathrm{pmol} / \mathrm{mg}$ collagen, respectively (control rats: $1.1 \pm 0.1 \mathrm{pmol} / \mathrm{mg}$ collagen). A similar pattern was observed for both glycation or oxidation-related fluorescence. The group of rats with poor control always showed elevated average values when compared to rats with good control, with a relative increase of over $200 \%$. The results emphasize the role of good glycaemic control in preventing the growth of glycation or oxidation end-products in collagen. On comparison between the general mean level of all glycated haemoglobin and the mean pentosidine level of the three groups, a very good exponential correlation was found $(r=0.993, p<0.001)$. The fluorescence values presented a less strong relationship, but a correlation with glycaemic control was still present. If the post-translational modifications of proteins play a leading role in the pathogenesis of complications it is possible to conclude that strict glycaemic control, obtained by accurate insulin therapy can prevent them by inhibiting the non-enzymatic modification of proteins and delaying their accumulation in collagen. The therapeutic implications are obvious. [D iabetologia (1996) 39: 1440-1447]

Keywords Glycation, oxidation, advanced glycation end products, pentosidine, fluorescence, collagen, non-enzymatic modification, glycaemic control, protein adducts.
The recently concluded $D$ iabetes Control and Complications Trial [1] is a milestone in understanding the development of complications in insulin-dependent diabetes mellitus. Patients followed over 6 years

Received: 23 M arch 1996 and in final revised form: 29 A ugust 1996

Corresponding author: P. O detti, M D, DIM I, Viale B enedetto XV, 6, I-16132 G enoa, I taly

A bbreviations: ND, N on-diabetic; IT, intensive therapy; CT, conventional therapy; GHb, glycated haemoglobin; HPLC, high pressure liquid chromatography; MDA, malondialdehyde; HNE, hydroxynonenal. showed a lower incidence of microvascular and neurological complications with a better glycaemic control. The conclusion of this large longitudinal study is that strict glycaemic control is the best way to delay the onset of complications, focusing on the importance of hyperglycaemia in the pathogenic mechanism [1]. The perturbation induced by hyperglycaemia leads to damage through several insulin-independent enzymatic pathways or by spontaneous postsynthetic protein modifications [2, 3]. N on-enzymatic glycation gives rise over time to a series of irreversible compounds with the formation of cross-links in extracellular matrix, alterations in cells and in nucleic acids $[4,5]$, and generates reactive free radicals 
through auto-oxidation of A madori product and/or glycated collagen [6, 7]. Furthermore by-products (aldehydes) of lipid oxidation, binding amino or sulfhydryl groups [8, 9], are also able to form adducts with proteins, contributing to the tissue damage.

A clear interconnection exists between glycation and oxidation [10-17]. There are two general hypotheses on the importance of these modifications: 1) a prevailing role of auto-oxidation as a leading factor in the pathogenesis of conformational changes, breaks, cross-links and formation of fluorescent endproducts $[12,16]$; 2) the prevalence of glucose and other molecules as protein modifiers, with the oxidation steps thought to be collateral contributors of a main event, the $\mathrm{M}$ aillard reaction $[14,15]$.

Several strong experimental studies indicate a role for non-enzymatic modifications in the development of diabetic sequelae [18-22]; however, a restricted number of in vivo studies have been performed to prove this relationship and study the effect of good glycaemic control, as the number of available markers is limited [23-25].

Since both glycation end-products and protein modifications by lipoperoxidation by-products are fluorescent [26-29] it is possible to take advantage of this characteristic to measure these products. M oreover a specific assay has been developed recently to quantify the concentration of pentosidine, a well characterized advanced glycation end-product [30].

This work evaluates the level of glycation and lipoperoxidation fluorescent compounds and the pentosidine content in subcutaneous collagen of B B/Wor diabetic rats, a strain considered an excellent animal model for human insulin-dependent diabetes. The effect of intensive metabolic control in protection against the formation and accumulation of glycation and lipoperoxidation derived compounds has been also examined.

\section{Materials and methods}

A nimals. Thirty diabetes-prone BB/Wor/Mol/BB male rats purchased from $M$ öllegaard $L t d$. (Skensved, D enmark) were randomly caged in groups of two and fed with standard diet (Piccioni Spa, Milan, Italy). D iabetes resistant B B $/$ or/M ol/ W $B$ rats were used as control group $(n=12)$.

The animals were housed until the programmed age for study was reached $(1,3$, and 6 months after the onset of diabetes). A II rats were maintained at $22-24^{\circ} \mathrm{C}$ with $12 \mathrm{~h}$ dark/light cycle, following common procedures for good animal care. $\mathrm{B}$ lood glucose was determined with reactive strips ( $\mathrm{H}$ aemoglucotest; Boehringher Mannheim Italia Spa, M ilan, Italy) and read with reflectometer ( $R$ eflolux $S$; B oehringher $M$ annheim) three times per week by drawing blood from a tail vein.

Glycated haemoglobin ( $\mathrm{GHb}$ ) levels were measured monthly by affinity chromatography (G lycaffin; I solab, A kron, O hio, USA ). A blood glucose over $11 \mathrm{mmol} / \mathrm{l}$ was considered indicative of diabetes onset, which occurred at 8-12 weeks of age.
O nce diabetes was confirmed (two consecutive hyperglycaemic values) insulin therapy was started. A subcutaneous slow-release implant of stearate insulin (Limplant; Linshin Inc., Canada) was used, adjusting the number of implants to achieve a good or fair-to-poor glycaemic control.

$D$ iabetic rats were randomly divided into two groups: one group intensively treated with insulin, whose blood glucose was maintained under $11 \mathrm{mmol} / \mathrm{l}$ (IT) and one with a conventional standardized insulin therapy, whose blood glucose was often beyond $16 \mathrm{mmol} / \mathrm{l}$ (CT). The first group received 1.5 times more insulin than the second group.

Sample preparation. A s programmed for diabetes duration, animals were killed after anaesthesia with intraperitoneal injection of sodium pentobarbital $(65 \mathrm{mg} / \mathrm{kg})$. Blood was drawn from the inferior vena cava and aliquots were used for the last measurement of glucose and $\mathrm{GHb}$. A midline incision in the skin of the abdomen was made and a sample of subcutaneous connective tissue was removed. A II fragments of muscular tissue were excised from connective tissue. The samples were washed thoroughly in normotonic saline solution and were frozen and stored at $-80^{\circ} \mathrm{C}$ until used for measurements. A small amount of collagen ( $20 \mathrm{mg}$ ) was finely minced and homogenized in ice-cold phosphate buffer saline $0.1 \mathrm{~mol} / \mathrm{l}(\mathrm{pH} 7.4$ ) with a Polytron homogenizer (K inematica, L ucerne, Switzerland), set at level 3 for 2-3 min. Lipids were extracted from the tissue with chloroform/methanol $(2: 1)$ by mild shaking overnight. The pellets were washed with methanol and water


fer ( $\mathrm{pH} 7.4$ ) with $1 \mathrm{~mol} / \mathrm{l} \mathrm{NaCl}$ and freed from soluble protein by washing with H PLC-grade water. The remaining tissue was digested for $24 \mathrm{~h}$ (at $37^{\circ} \mathrm{C}$ with mild shaking) with purified collagenase (type VII, Sigma, St.Louis, M o., USA) in HEPES buffer $\left(0.02 \mathrm{~mol} / \mathrm{l}, \mathrm{pH}\right.$ 7.5) containing $0.01 \mathrm{~mol} / \mathrm{C} \mathrm{CaCl}_{2}$. The supernatant was used for the determination of hydroxyproline content and fluorescence. The undigested collagen amounted to less than $20 \%$ of the total.

E nd-product determination. Fluorescence intensity was determined in the digests with a L55B Perkin-Elmer (Verkauf $\mathrm{GmBH}, \mathrm{M}$ unchen, G ermany) spectrophotofluorometer at: a) $440 \mathrm{~nm}$ upon excitation of $370 \mathrm{~nm}$ for M aillard products related fluorescence [31]; b) $335 \mathrm{~nm}$ excitation and $385 \mathrm{~nm}$ emission for pentosidine-like products (32); c) $460 \mathrm{~nm}$ upon excitation of $390 \mathrm{~nm}$ and of $356 \mathrm{~nm}$, which are the specific wavelengths for malondiadehyde (MDA) and hydroxynonenal (HNE) protein-adducts [33]. A hydroxyproline assay was performed according to the method of Stegemann and Stalder [34] to give relative collagen content. The intensity of fluorescence was expressed in arbitrary units of fluorescence (A U F) per milligram of hydroxyproline. Twenty mg of subcutaneous collagen was used for pentosidine quantitation [30]. A fter homogenization and delipidization, the pellets, washed at least twice with phosphate buffer $(0.1 \mathrm{~mol} / \mathrm{l}, \mathrm{pH} 7.4)$, were hydrolysed in $2 \mathrm{ml}$ of $\mathrm{HCl} 6 \mathrm{~N}$, under $\mathrm{N}_{2}$ atmosphere for $24 \mathrm{~h}$ at $110^{\circ} \mathrm{C}$ in borosilicate tubes with a screw cap. A fter hydrolysis, acid was evaporated with Modulyo lyophilizer (E dwards A Ito Vuoto S. p. A., M ilan, Italy) and each sample was reconstituted in water containing $0.01 \mathrm{~mol} / \mathrm{l}$ heptafluorobutyric acid (Pierce, Prodotti Gianni, Milan, Italy) and filtered through $0.45 \mu \mathrm{m}$ pore diameter filter (UItrafree MC, M illipore, Milan, I taly).

Pentosidine was determined in reconstituted samples by reverse phase chromatography $(25 \times 0.46 \mathrm{~cm}$ Vydac type 218TP $(10 \mu \mathrm{m})$ C-18 column, Separation G roup, Hesperia, Calif., U SA ) on a Waters H PL C system (WA T 717 as autosampler, WA T510 as pump and an NEC 486 Image computer as 
controller, Waters, Milan, Italy). "Millenium software" was used to manage the chromatography.

Separations were made with a linear gradient program of $10-17 \%$ acetonitrile from 0 to $22 \mathrm{~min}$, containing water ( $\mathrm{M}$ illiQ, M illipore) and heptafluorobutyric acid $(0.01 \mathrm{~mol} / \mathrm{l})$ as a counter ion [30]. The effluent was scanned by a $470 \mathrm{~W}$ aters fluorescent detector set at $385 \mathrm{~nm}$ emission upon $335 \mathrm{~nm}$ excitation wavelength. A ttenuation was fixed at 4, gain at $\times 100$ and filter at $1.5 \mathrm{~s}$. The pentosidine area was collected, dried and resuspended in $0.02 \mathrm{~mol} / \mathrm{l}$ sodium acetate buffer $(\mathrm{pH} 4.7)$ for a further separation, since pentosidine peak was not well resolved. The collected fraction was loaded onto a cation exchange column (SP-5PW Waters) with a mobile phase, characterized by a curvilinear gradient of $\mathrm{NaCl}$ from 0 to $0.06 \mathrm{~mol} / \mathrm{l}$ (from 0 to $40 \mathrm{~min}$ ) in sodium acetate $0.02 \mathrm{~mol} / / \mathrm{l}(\mathrm{pH} \mathrm{4.5)}$ [30]. The fluorimeter was set as previously reported for the reverse phase column. A pentosidine synthetic standard was injected at the beginning of every run to quantitate the level in the sample by peak area comparison.

Statistical evaluation. A nalysis of variance and Tukey-K ramer post-test with multiple comparisons were used. A nalysis of linear or non-linear regression and correspondent coefficient of correlation was performed to assess the fit between the two parameters. The fluorescence values were normalized for age and duration of diabetes as previously described [35]. B riefly adjustment was made using the graph co-ordinates of variables and the slope of the computed regression line of non-diabetic rats.

A two-tail $p$ value was considered significant if less than 0.05. D ata are expressed as mean \pm SE $M$.

\section{Results}

$R$ at growth was regular until the onset of diabetes; diabetic animals gained weight slower than controls: after 24 weeks of diabetes the body weight was lower than in control (ND) animals (Fig. 1). However, the group submitted to intensive insulin therapy (IT) showed a more regular body weight gain than the group on conventional therapy (CT). A fter onset of diabetes blood glucose sharply increased. In the CT group blood glucose rapidly reached $20 \mathrm{mmol} / \mathrm{l}$ and was only partially corrected by the therapy; GHb gradually achieved levels over $8 \%$, but sometimes peaked at $14 \%$ (ND: $n=54,4.2 \pm 0.1 \%$ and CT: $n=90,8.8 \pm 0.3 \%)$. In the IT group the glucose level remained beyond normal concentrations but only occasionally exceeded $12 \mathrm{mmol} / \mathrm{l}$; moreover rats seldom presented hypoglycaemia (blood glucose lower than $2.5 \mathrm{mmol} / \mathrm{l}) ; \mathrm{G} \mathrm{H}$ b ranged between 4 and $8 \%$ with an overall average of $6.0 \pm 0.1 \% \quad(n=90) \quad$ (A NOVA : $F=93.3, p<0.001 ; N D$ vs IT, ND vs CT and CT vs IT, all $p<0.001$ ) (Fig. 2).

$\mathrm{R}$ aw tissue fluorescence in non-diabetic rats was similar to that obtained in another strain of non-diabetic rats, in which a slow initial increase was observed during youth and middle age [17]: both collagen glycation and oxidation-related fluorescence intensities increased slightly during the observation period, the $330 \mathrm{~nm} / 420 \mathrm{~nm}$ and $356 \mathrm{~nm} / 460 \mathrm{~nm}$ fluorescence

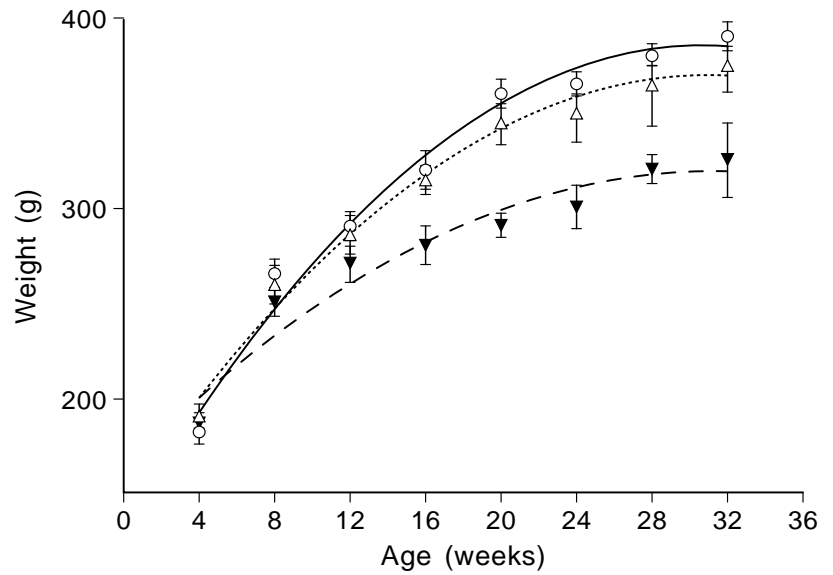

Fig. 1. Increase of body weight in control $(\bigcirc)$, diabetic with good (IT $\triangle$ ) or poor (CT $\boldsymbol{\nabla}$ ) glycaemic control rats

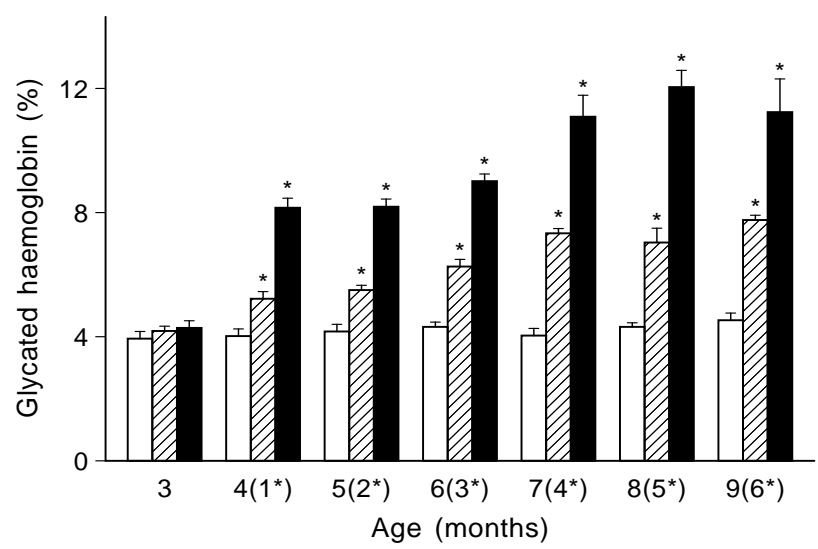

Fig. 2. Glycated haemoglobin levels during the observation period. $B$ ars represent mean \pm SE M ; non-diabetic (ND $\square$ ); diabetic in intensive insulin therapy (IT $\mathbb{Z}$ ); diabetic in conventional therapy (CT $\square$ ); months of diabetes duration in brackets. $* p<0.05$ vs correspondent basal value

showed the most increase (Fig. 3). The $370 / 440 \mathrm{~nm}$ fluorescence is usually related to general advanced glycation end-products and the $335 / 385 \mathrm{~nm}$ fluorescence to pentosidine-like compounds, since pentosidine represents only $30 \%$ of this fluorescence [33, 34]. A weak increase was observed in the ND group, while in both diabetic groups the fluorescence values distinctly rose. However, in the IT group, though the 370/440 $\mathrm{nm}$ fluorescence was higher than in ND, it remained steady over time, while in the CT group it had more than doubled after 1 month of diabetes and had further increased at 6 months of diabetes. $0 \mathrm{n}$ the other hand the 335/385 nm fluorescence showed an apparently slower increase after the onset of diabetes, but a clear increase was noticeable during the observation. The level in the CT group was higher than in the IT group (Table 1) and at the end of the study it was three times higher than at the starting level.

Both wavelengths of oxidation-related fluorescence showed an increase with aging in the ND rats. 
Table 1. A nalysis of variance (F) and post-tests (Tukey-K ramer) in non-diabetic (ND), diabetic in intensive (IT) and conventional (CT) insulin therapy

\begin{tabular}{|c|c|c|c|c|c|}
\hline $\begin{array}{l}\text { Fluorescence } \\
\text { (excitation } \mathrm{nm} / \\
\text { emission } \mathrm{nm} \text { ) }\end{array}$ & $\begin{array}{l}\text { A ge } \\
\text { (months) }\end{array}$ & $F$ & ND vs IT & ND vs C T & IT vsCT \\
\hline $370 \mathrm{~nm} / 440 \mathrm{~nm}$ & $\begin{array}{l}4 \\
6 \\
9\end{array}$ & $\begin{array}{r}6.2^{\mathrm{a}} \\
11.3^{\mathrm{b}} \\
32.9^{\mathrm{c}}\end{array}$ & $\begin{array}{l}\text { NS } \\
\text { NS } \\
\text { NS }\end{array}$ & $\begin{array}{l}<0.05 \\
<0.01 \\
<0.001\end{array}$ & $\begin{array}{l}\text { NS } \\
<0.05 \\
<0.001\end{array}$ \\
\hline $335 \mathrm{~nm} / 385 \mathrm{~nm}$ & $\begin{array}{l}4 \\
6 \\
9\end{array}$ & $\begin{array}{c}3.8 \\
26.5^{c} \\
25.5^{c}\end{array}$ & $\begin{array}{l}\text { NS } \\
<0.05 \\
<0.05\end{array}$ & $\begin{array}{l}\text { NS } \\
<0.001 \\
<0.001\end{array}$ & $\begin{array}{l}\text { NS } \\
<0.01 \\
<0.01\end{array}$ \\
\hline $356 \mathrm{~nm} / 460 \mathrm{~nm}$ & $\begin{array}{l}4 \\
6 \\
9\end{array}$ & $\begin{array}{l}19.4^{c} \\
19.5^{c} \\
19.8^{c}\end{array}$ & $\begin{array}{l}\text { NS } \\
\text { NS } \\
\text { NS }\end{array}$ & $\begin{array}{l}<0.001 \\
<0.001 \\
<0.001\end{array}$ & $\begin{array}{l}<0.01 \\
<0.01 \\
<0.01\end{array}$ \\
\hline $390 \mathrm{~nm} / 460 \mathrm{~nm}$ & $\begin{array}{l}4 \\
6 \\
9\end{array}$ & $\begin{array}{l}3.0 \\
1.4 \\
8.7^{b}\end{array}$ & $\begin{array}{l}\text { NS } \\
\text { NS } \\
\text { NS }\end{array}$ & $\begin{array}{l}\text { NS } \\
\text { NS } \\
<0.05\end{array}$ & $\begin{array}{l}\text { NS } \\
\text { NS } \\
<0.05\end{array}$ \\
\hline $330 \mathrm{~nm} / 420 \mathrm{~nm}$ & $\begin{array}{l}4 \\
6 \\
9\end{array}$ & $\begin{array}{l}19.1^{c} \\
19.0^{c} \\
41.7^{c}\end{array}$ & $\begin{array}{l}\text { NS } \\
\text { NS } \\
\text { NS }\end{array}$ & $\begin{array}{l}<0.001 \\
<0.01 \\
<0.001\end{array}$ & $\begin{array}{l}<0.01 \\
<0.001 \\
<0.001\end{array}$ \\
\hline
\end{tabular}

${ }^{a} p<0.05,{ }^{b} p<0.01,{ }^{c} p<0.001$

A fter the onset of diabetes the $356 / 460 \mathrm{~nm}$ fluorescence ( $\mathrm{HNE}$-protein related) underwent a moderate, but significant increase if the glycaemic control was good (IT), a dramatic increase was evident if the blood glucose was poorly controlled (CT). A different pattern was exhibited by the MDA -related fluorescence $(390 / 460 \mathrm{~nm})$, indeed only at 6 months of diabetes a significant higher level was reported for the CT group (Fig. 3, Table 1).

In order to attain a more complete profile, maps of collagen linked fluorescence were explored by sequential evaluation of fluorescence spectra for each collagen sample. A $n$ evident maximum was found around $330 / 420 \mathrm{~nm}$. A very slight increase in 330/420 fluorescence was detected in the non-diabetic and in the IT group; whereas in the CT group an early and significant increase was observed after 1 month of diabetes, the increase being even greater at the end of the study; interestingly, the IT group levels were never significantly different from the ND levels (Fig. 4, Table 1).

The comparison of the three groups of rats with each other at 1, 3 and 6 months indicated that intensive insulin treatment had noteworthy consequences on fluorescence accumulation (Table 1). A t 1, 3 and 6 months of diabetes, all fluorescence levels in the IT group were not significantly higher than in similar aged NDs, the only exception being the $335 \mathrm{~nm} / 385$ $\mathrm{nm}$ fluorescence, higher at 3 and 6 months $(p<0.05)$. Treatment efficacy was still more evident comparing CTs with ITs and NDs. A clear-cut difference was found for each fluorescence and at each step studied (Table 1). The few differences between the non-diabetic group and diabetic rats in intensive treatment showed an efficient inhibition on non-enzymatic reactions by good control. Pentosidine, a sensitive marker of glycation, showed a similar course: all groups, at the end of the study, had significantly higher values in comparison with the concentration observed during the first month of diabetes (corresponding to 4 months of age for the ND group; Fig. 3). Pentosidine content in IT rats was roughly superimposable on that of the control group at 1, 3 and even after 6 months of diabetes; at 6 months the CT group was at the highest levels, significantly more elevated than ND and IT groups ( $1.1 \pm 0.2$ [ND ], $2.1 \pm 0.5$ [IT] and $13 \pm 5$ [CT] $\mathrm{pmol} / \mathrm{mg}$ collagen; ANOVA $\mathrm{F}=6.9 ; \mathrm{ND}$ VS $C T$, $\mathrm{p}<0.05$ and IT vSCT, $\mathrm{p}<0.05)$.

A study of the relationships between glycation- or oxidation-related fluorescence, pentosidine and the glucose control parameters ( $\mathrm{G} \mathrm{H}$ b and blood glucose) was performed. A s expected, a significant coefficient of correlation was found between $\mathrm{G} \mathrm{H} \mathrm{b}$ and the mean of all previous blood glucose determinations $(n=142$; $y=2.29+1.11 x, \quad r=0.639, \quad p<0.001 ; \quad$ Fig. 4). The mean of all blood glucose determinations before killing rats was correlated with tissue pentosidine with a non - linear correlation $(\mathrm{n}=30 ; \mathrm{y}=1.5+$ $\left.0.41 x+0.012 x^{2} ; r=0.618, p<0.01\right)$. When the mean of $\mathrm{G} \mathrm{H}$ b at different ages in the three groupswas correlated with pentosidine it exhibited a striking non-linear regression $\left(y=0.013 * e^{0.037 x} ; r=0.993 ; p<0.001\right.$; Fig. 4). Significant correlations were also observed between fluorescence values and average of $\mathrm{GH}$ b: the strongest correlation coefficient was found with the $390 \mathrm{~nm} / 460 \mathrm{~nm}$ fluorescence (Table 2). E ven stronger correlations of fluorescence with pentosidine were found, particularly with the $370 \mathrm{~nm} / 440 \mathrm{~nm}$ and with $335 \mathrm{~nm} / 385 \mathrm{~nm}$ fluorescence (Table 2). In order to avoid the effect caused by possible confounding factors we adjusted the value of pentosidine for age and duration of diabetes. A s expected, the age factor influenced the accumulation of glycation end-products, but the diabetes-induced differences were still present and the correlation coefficients basically not affected.

\section{Discussion}

N on-enzymatic modification of collagen is a well recognized feature of diabetes and is implicated in the pathogenesis of complications. There are no doubts that non-enzymatic glycation and oxidative stress are important reactions in the damage of collagen protein in diabetes $[4-6,8,11,13-25]$, but little is known about the kinetics of collagen after non-enzymatic modification. E arly glycation (exosyllysine) is directly related to the ambient glucose concentration, but its accumulation in blood and tissues is saturable $[36,37]$. A specific enzymatic degradation of A madori product has been reported recently, but the influence of this pathway does not appear considerable $[38,39]$. Conversely the amount of irreversible 

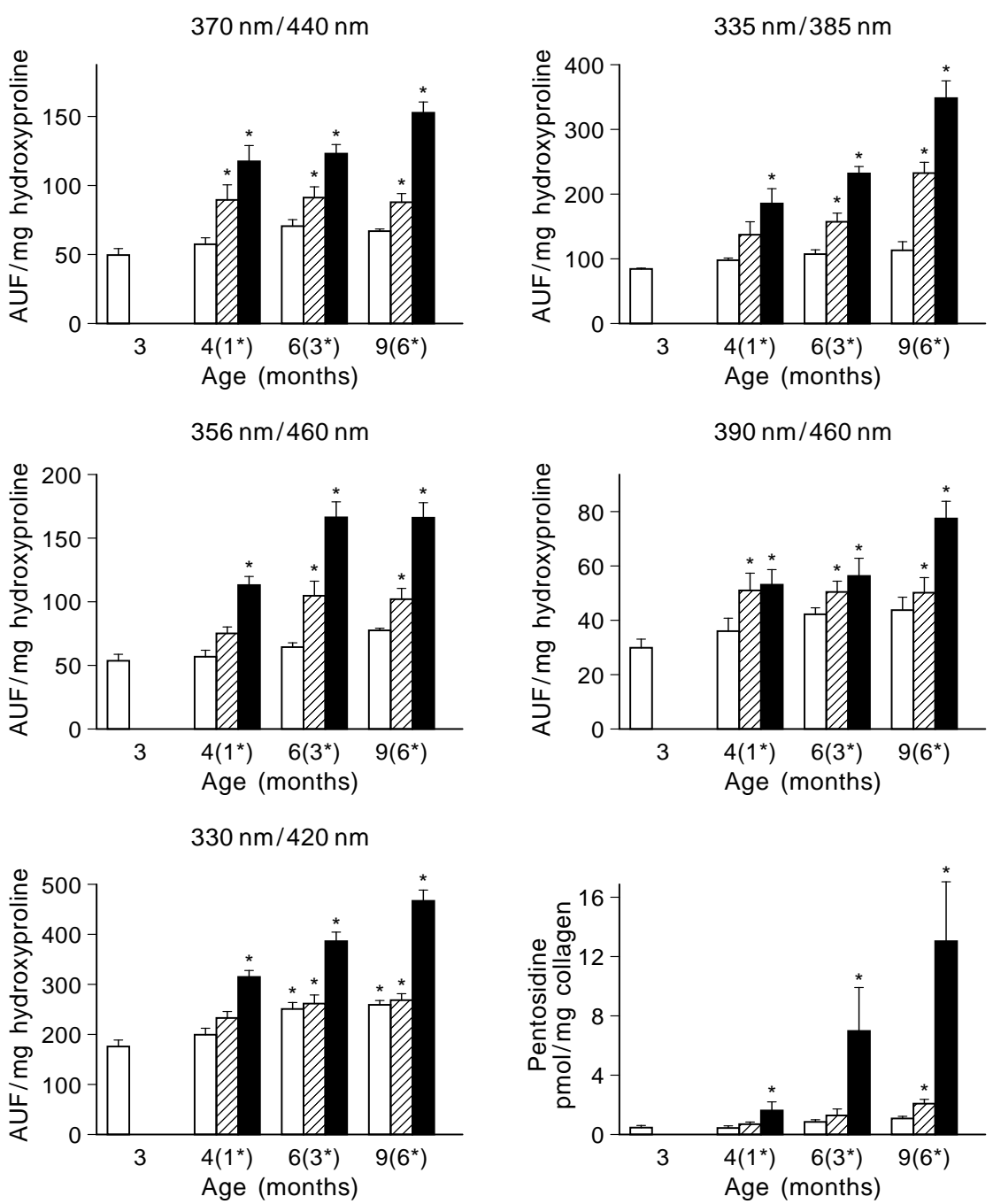

Fig. 3. E ffect of good or poor glycaemic control on the fluorescence and pentosidine level in subcutaneous collagen of diabetic rats. A nimals were killed after 1,3 , and 6 months of diabetes; at the time non-diabetic rats of the same age were also killed. Bars represent mean \pm SEM ; non-diabetic ( $\square$ ND, $n=12)$; diabetic in intensive insulin therapy (खIT, $n=15)$; diabetic in conventional therapy ( $\mathrm{CT}, \mathrm{n}=15$ ); A U F, A rbitrary $U$ nits of fluorescence. $M$ onths of diabetes duration in brackets $* p<0.05$ vs correspondent basal value

end-products depends mainly, but not only [40,41], on the degree of hyperglycaemia, giving rise to irreversible and fluorescent or non-fluorescent final products. E nzymatic degradation for advanced glycation end product ( $A G E$ ) reactive intermediates has been postulated [42], but it is certainly slow and difficult; A GE removal from tissue is largely hypothetical. Thus, the pool of collagen modified by glycation and oxidation products may be considered al most insoluble, with a negligible turnover; therefore their tissue growth is not easily restricted.

These observations explain the observed age-related accumulation and sharp, impressive acceleration

that occurred with diabetes. This study confirms that diabetes induces an increase of $A G E$ in collagen, evaluated by means of fluorescence and pentosidine.

Increased attention has been directed toward oxidative stress and related events, raising new speculative hypotheses of tissue damage [7, 8, 16, 28, 43-47]. Glycation related fluorescence showed a linear increase in intensity after the onset of diabetes, especially in the CT group, whereas the oxidation-related fluorescence manifested a time gap, but it was particularly sensitive to poor glycaemic control. Thus, diabetes induced a marked increase of fluorescence intensity at all examined wavelengths. $\mathrm{H}$ owever, in the IT group, after a slight increase, the level remained steadier, throughout the study, than in the CT group, where, as expected, an impressive effect was detected after 3 and 6 months of diabetes (Fig. 3).

The present data indicate an increase in fluorescence corresponding to glycation and in fluorescence related to the lipoperoxidation adducts. Thus, it appears that non-enzymatic glycation and oxidation are strictly connected and both contribute to the modification of biological structures; in vitro studies have provided firm evidence in this direction $[6,11$, 

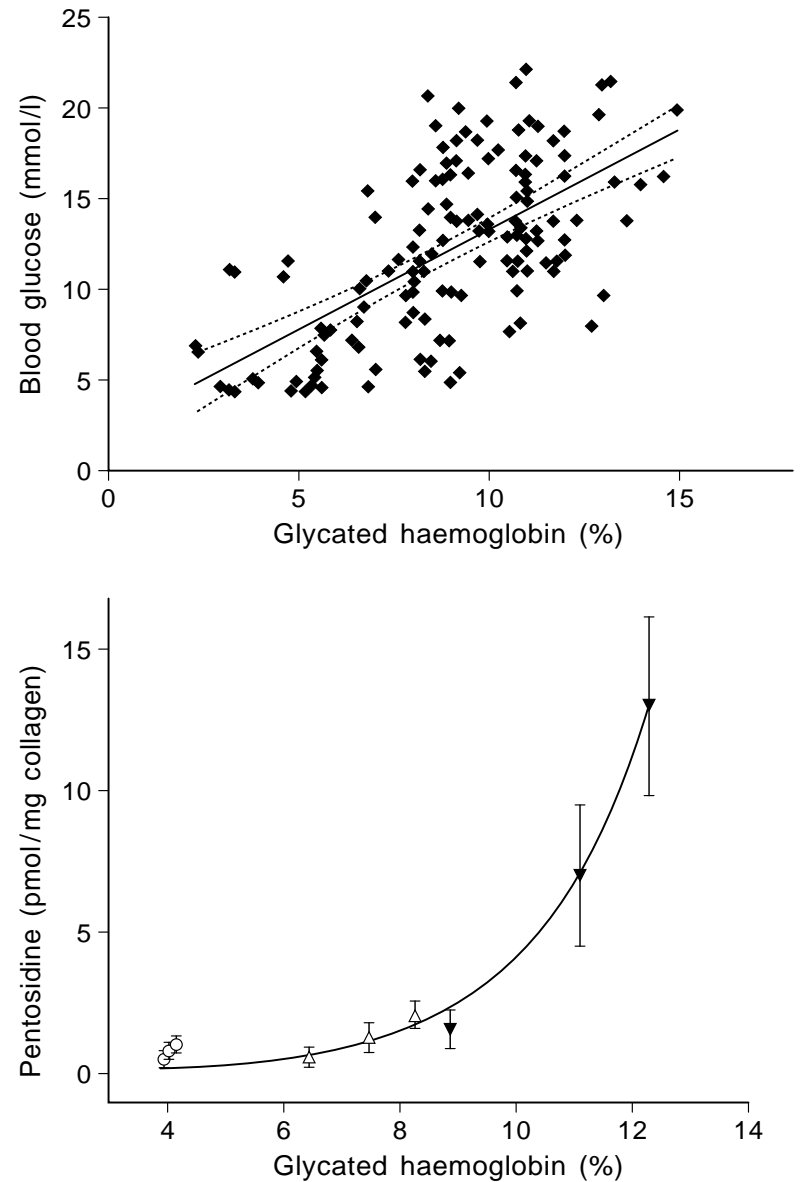

Fig. 4. U pper panel, blood glucose ( $\mathrm{mmol} / \mathrm{l})$ vs glycated haemoglobin (\%) of non-diabetic and diabetic rats. Blood glucose values are the averages of all blood glucose determinations before the value of glycated haemoglobin ( $n=142$, $y=2.29+1.11 x, r=0.639, p<0.001)$. L ower panel, non-linear correlation between the averages of pentosidine ( $\mathrm{pmol} / \mathrm{mg}$ collagen) at 1, 3 and 6 months of diabetes and the averages of all glycated haemoglobin (\%) determinations before killing in non-diabetic (ND $\bigcirc$ ), diabetic in good (IT $\triangle$ ) and poor (CT ק) glycaemic control rats $\left(n=6 ; y=0.013 * \mathrm{e}^{0.037} ; r=0.993\right.$; $\mathrm{p}<0.001)$

$13,14,16]$. A strong correlation was noticed between the glycation and the oxidation-related fluorescence, this was expected as we had already found the same relationship during aging [17].

What was surprising was the correlation found between the oxidation parameters and glycaemic control, suggesting a direct relationship between worsening of glucose control and the formation of protein oxidation adducts. We are not aware of any existent contribution on this issue in the literature - in vivo at least. In the previous studies a fair or poor correlation was found between glycation related fluorescence, pentosidine and glycaemic control [18-25]. For the elaboration of our data we used the average of all the available $\mathrm{GH}$ b values of the antecedent period and the result was a striking significant correlation (Fig. 4). The average of $\mathrm{GH} \mathrm{b}$ values and pentosidine
Table 2. Coefficients of correlation between fluorescence levels and glycated haemoglobin or pentosidine

\begin{tabular}{llllll}
\hline & \multicolumn{5}{c}{ Fluorescence (excitation nm/emission nm) } \\
\cline { 2 - 6 } & $370 / 440$ & $335 / 385$ & $356 / 460$ & $390 / 460$ & $330 / 420$ \\
\hline Glycated & & & & & \\
haemoglobin & $0.46^{\mathrm{b}}$ & $0.48^{\mathrm{b}}$ & $0.45^{\mathrm{b}}$ & $0.50^{\mathrm{b}}$ & $0.44^{\mathrm{b}}$ \\
Pentosidine & $0.83^{\mathrm{c}}$ & $0.80^{\mathrm{c}}$ & $0.71^{\mathrm{c}}$ & $0.67^{\mathrm{c}}$ & $0.72^{\mathrm{c}}$ \\
\hline
\end{tabular}

${ }^{b} p<0.01,{ }^{c} p<0.001$

showed an exponential correlation, suggesting that the level of this A GE marker may reflect the glycaemic level over an extended period of time, longer than that recognized by markers of early phases of glycation ( $\mathrm{GH}$ b). Further, the shape of the exponential curve is easily explicable: the early glycation, i.e. formation of the A madori product, is a saturable reaction and no more than $15-18 \%$ of haemoglobin can be modified even during a prolonged and chronic hyperglycaemia. Conversely, pentosidine does not appear to reach saturation, or, at least, may have a much higher level of tissue saturation, continuing to accumulate in skin collagen. It is possible that the accumulation of $A G E$ might be the direct effect of chronic hyperglycaemia: increasing the level of blood glucose increases accumulation.

M oreover, the disposal mechanism of A GE [48, 49] is likely slow or not expandable and in the face of a higher concentration of glucose and other precursors the removal may not be active enough to prevent the tissue accumulation.

A linear correlation was observed between $\mathrm{GH}$ b and the collagen oxidation-related fluorescence. The strict relationships found confirm that blood glucose level is directly implicated in the genesis of the fluorescent molecules derived from the two pathways (glycation and oxidation). We demonstrated that an early start in treatment makes it possible to slow down non-enzymatic glycation and oxidative stress, both activated by poor glycaemic control.

Previous studies showed a correlation between collagen post-translational modifications and presence of diabetic complications [18-22]. However, other studies have reported difficulties in repairing the damage produced in collagen. In human diabetic patients, after 1-3 years, the most favourable glycaemic control obtained a reduction as small as $10 \%$ of collagen fluorescent products [23]. In other studies, after 4 months and after 1.5 years of good glycaemic control, no verifiable changes were reported [24, 25]. M oreover, a collateral D CCT study found that intensive treatment led to collagen-linked fluorescence and pentosidine lower than that of patients on conventional treatment [50]. In our study the difference between control rats and diabetic rats with good control, initiated early, was low and not significant, whereas the $C T$ group showed dramatically higher values in all markers. Consequently, intensive treatment must 
be initiated as early as possible and maintained to achieve the lowest level of A GE, which, on the basis of recent evidence, means a low degree of complications.

These patient studies suggest that once the tissue is saturated and cross-linked, it is very difficult to turnover. It is reasonable to suppose that the alternation of good and poor control induces complications in any case because of the inability to remove the accumulated damages during the good control period. A study of this risk in animals is needed.

In conclusion, our data support the hypothesis that hyperglycaemia leads to collagen browning and oxidation damage, the former appearing to be faster and more intense. The data, however, suggest that the two pathways are biochemically and structurally related and have to be included in the so-called $\mathrm{M}$ aillard reaction. Good glycaemic control, initiated immediately after the onset of diabetes, is able to prevent the increase of both reactions.

A cknowledgements. This work was supported by CNR (G rant \# 91.00385, \# 93.02041CT14, 94.00297.CT 14) and MURST Grants. We acknowledge the skilful technical assistance of Mr. G. Maloberti and Mr. G. Catalano for the assistance in the animal care. The authors wish to thank Dr. V.M. M onnier (CWRU, Cleveland, O hio, USA) for supplying pure standard of pentosidine.

\section{References}

1. The Diabetes Control and Complications Trial Research $G$ roup (1993) The effect of intensive treatment of diabetes on the development and progression of long term complications in insulin-dependent diabetes mellitus. N Engl J M ed 329: 977-986

2. K reisberg JI (1992) Hyperglycemia and microangiopathy. $D$ irect regulation by glucose of microvascular cells. $L$ ab Invest 67: 416-426

3. Ruderman NB, Williamson JR, Brownlee M (1992) Glucose and diabetes vascular disease. FA SE B J 6: 2905-2914

4. B rownlee M (1994) G lycation and diabetic complications. D iabetes 43: 836-841

5. B ucala R , Cerami A , V lassara H (1995) A dvanced glycosylation end-products in diabetic complications. Diabetes R eviews 3: 258-268

6. Fu M , K necht KJ, Thorpe S et al. (1992) R ole of oxygen in cross-linking and chemical modification of collagen by glucose. D iabetes 41 (Suppl 2):42-48

7. Gillery P, M onboisse J C, M aquart FX et al. (1988) Glycation of proteins as a source of superoxide. D iabète $M$ etab 14: $25-30$

8. Fujimori E (1989) Cross-linking and fluorescence changes of collagen by glycation and oxidation. Biochim Biophys A cta 998: 105-110

9. T sushida M, M iura T, M izutani K et al. (1985) Fluorescent substances in mouse and human sera as a parameter of in vivo lipid peroxidation. Biochim Biophys A cta 834: 196204

10. Sakurai T, Tsuchiya S (1988) Superoxide production from nonenzymatically glycated protein. FE BS Lett 236: 406410
11. H icks M , D elbridge L, Y ue DK et al. (1988) Catalysis of lipid peroxidation by glucose and glycosylated proteins. B iochem Biophys R es Commun 151: 649-655

12. H unt JV, Smith CCT, Wolff SP (1990) A utoxidative glycosylation and possible involvement of peroxides and free radicals in LDL modification by glucose. Diabetes 39 : 1420- 1424

13. Chace KV, Carubelli R, Nordquist RE (1991) The role of nonenzymatic glycosylation, transition metals, and free radicals in the formation of collagen aggregates. A rch B iochem Biophys 288: 473-480

14. B aynes J W (1991) R ole of oxidative stress in development of complications in diabetes. D iabetes 40: 405-412

15. M onnier V M, Sell D R, Nagaraj R H et al. (1992) M aillard reaction-mediated molecular damage to extracellular matrix and other tissue proteins in diabetes, aging and uremia. D iabetes 41(Suppl 2):36-41

16. Wolff SP (1993) Diabetes mellitus and free radicals. $\mathrm{Br}$ M ed B ull 49: 642-652

17. O detti P, Pronzato MA, Noberasco G et al. (1994) Relationships between glycation and oxidation related fluorescences in rat collagen during aging. $L$ ab Invest 70: 61-67

18. M onnier V M , V ishwanath V, Frank KE et al. (1986) R elation between complications of type I diabetes mellitus and collagen-linked fluorescence. N Engl J M ed 314: 403-408

19. Dominiczak M H, B ell J, Cox NH et al. (1990) Increased collagen-linked fluorescence in skin of young patients with type I diabetes mellitus. D iabetes Care 13: 468-472

20. Sell DR, L apolla A, O detti P et al. (1992) Pentosidine formation in skin correlates with severity of complications in individuals with long-standing ID D M. Diabetes 41: 12861292

21. B eisswenger PJ, M oore L L, B rink-J ohnsen T et al. (1993) Increased collagen-linked pentosidine levels and advanced glycosylation end-products in early diabetic nephropathy. J Clin Invest 92: 212-217

22. B eisswenger PJ, Makita Z, Curphey TJ et al. (1995) Formation of immunochemical advanced glycosylation endproducts precedes and correlates with early manifestations of renal and retinal disease in diabetes. D iabetes 44: 824829

23. B eisswenger PJ, Moore LL, Curphey TJ (1993) Relationship between glycaemic control and collagen-linked advanced glycosylation end-products in type I diabetes. D iabetes Care 16: 689-694

24. Lyons TJ, Bailie KE, Dyer DG et al. (1991) Decrease in skin collagen glycation with improved glycaemic control in patients with insulin-dependent diabetes mellitus. J Clin Invest 87: 1910-1915

25. Salmela PI, Oikarinen A J, U kkola O et al. (1995) Improved metabolic control in patients with non-insulin dependent diabetes mellitus is associated with a slower accumulation of glycation products in collagen. E ur J Clin Invest 25: 494-500

26. Monnier VM, Kohn RR, Cerami A (1984) A ccelerated age-related browning of human collagen in diabetes mellitus. Proc N atl A cad Sci U SA 81: 583-587

27. L edl F, B eck J, Sengl M et al. (1989) Chemical pathways of the $M$ aillard reaction. In: B aynes JW, M onnier VM (eds) The $M$ aillard reaction in aging, diabetes and nutrition. Progr Biol Res 304: 23-42

28. K ikugawa K, B eppu M (1987) I nvolvement of lipid oxidation products in the formation of fluorescent and crosslinked proteins. Chem Phys L ipids 44: 277-296

29. H ouglum K, Filip M , Witzum J L et al. (1990) M alondialdehyde and 4-hydroxynonenal protein adducts in plasma and liver with iron overload. J Clin I nvest 86: 1991-1998 
30. O detti P, Fogarty J, Sell D R et al. (1992) Chromatographic quantitation of plasma and red blood cell pentosidine in diabetic and uremic subjects. D iabetes 41: 153-159

31. M onnier V M , Cerami A (1981) N onenzymatic browning in vivo: possible process for aging of long-lived protein. Science 211: 491-493

32. Neal SL, Sell DR, Thomas MP et al. (1989) Videofluorimetric analysis of aging human collagen. A nal L etters 22: 2747-2760

33. Carini R, M azzanti R, B iasi F et al. (1988) Fluorescent aldehyde-protein adducts in the blood serum of healthy alcoholics. In: Nordmann R, R ibiere C, R ouach H (eds) A Icohol toxicity and free radicals mechanisms. A dv Biosciences 71: $61-64$

34. Stegemann H, Stalder K (1967) Determination of hydroxyproline. Clin Chim A cta 18: 267-273

35. O detti P, Borgoglio A, Rolandi R (1992) A ge-related increase of collagen fluorescence in human subcutaneous tissue. M etabolism 41: 655-658

36. Higgins PJ, Bunn H F (1981) K inetic analysis of the nonenzymatic glycosylation of haemoglobin J Biol Chem 256: 5204-5208

37. Yue DK, M CL ennan S, Turtle JR (1983) Non-enzymatic glycosylation of tissue protein in diabetes in the rat. $D$ iabetologia 24: 377-381

38. A hmed M U, Thorpe SR, B aynes J W (1986) Identification of carboxymethyllysine as a degradation product of fructoselysine in glycated protein. J B iol Chem 261: 88168821

39. M ortensen H B , Christophersen C (1983) G lycosylation of human haemoglobin in red blood cells studied in vitro. $\mathrm{K} \mathrm{i-}$ netics of the formation and dissociation of haemoglobin A 1c. Clin Chim A cta 134: 317-326

40. Vander Jagt D L, R obinson B, Taylor KK et al. (1992) R eduction of trioses by NA D PH-dependent aldo-keto reductases: aldose reductase, methylglyoxal, and diabetic complications. J Biol Chem 267: 4364-4369
41. Nagaraj R H, Sell DR, Prabhakaram M et al. (1991) High correlation between pentosidine protein crosslinks and pigmentation implicates ascorbate oxidation in human lens senescence and cataractogenesis. Proc Natl A cad Sci U SA 88: 10257-10261

42. Takahashi M, Fujii J, Teshima T et al. (1993) Identity of a major 3-deoxyglucosone-reducing enzyme with aldehyde reductase in rat liver established by amino acid sequencing and CDNA expression. Gene 127: 249-253

43. H alliwell B, G utteridge J M C, Cross CE (1992) Free radicals, antioxidants, and human disease: where are we now? J L ab Clin Med 119: 598-620

44. H unt J V, D ean RT, Wolff SP (1988) H ydroxyl radical production and autoxidative glycosylation. G lucose autoxidation as the cause of protein damage in the experimental glycation model of diabetes mellitus and ageing. Biochem J 256: $205-212$

45. Wolff SP, D ean R T (1988) A Idehydes and ketoaldehydes in the non-enzymatic glycosylation of proteins. Biochem J 249: 617-619

46. J iang ZY, Wollard A CS, Wolff SP (1990) H ydrogen peroxide production during experimental protein glycation. FE B S L etter 268: 69-71

47. M ullarkey CJ, E delstein D, B rownlee M (1990) Free radical generation by early glycation products: a mechanism for accelerated atherogenesis in diabetes. Biochem Biophys R es Commun 173: 932-939

48. V lassara H (1992) Receptor-mediated interaction of advanced glycosylation end-products with cellular components within diabetic tissues. D iabetes 41(Suppl 1):52-56

49. Schmidt A M, H ori O, B rett J et al. (1994) Cellular receptors for advanced glycation end-products. A rterioscler Thromb 14: 1521-1528

50. M onnier V M, Sell D R, Fogarty J et al. (1995) The effect of intensive treatment on skin collagen abnormalities in ID D M . D iabetes 44[Suppl 1]:112A 